\title{
Biotypes, serotypes, and susceptibility to antibiotics of 60 Haemophilus influenzae strains from genitourinary tracts
}

\author{
I CASIN,* M J SANSON-LE PORS, * A FELTEN, $\dagger$ Y PEROL* \\ From the *Service de Bactériologie-Virologie, Hôpital Saint-Louis; and the †Service de Bactériologie, Hôpital \\ Lariboisière, Paris, France
}

SUMMARY Sixty strains of Haemophilus influenzae were isolated from the genitourinary tracts of adults: 19 from cervicovaginal secretions, one from a woman with bartholinitis, 37 from urethral exudates, and three from urine. Non-capsulated strains were recovered predominantly, and biotype III accounted for 28 isolates and biotype IV for 25.

Many of the $H$ influenzae strains were found to be resistant to one or more of the antibiotics commonly used against sexually transmitted diseases. Resistance to tetracycline was prevalent and was found in 17 of the strains. Ten strains were ampicillin resistant and $\beta$ lactamase producing. Kanamycin resistance was less common (two strains). Trospectomycin (U-6336F), a new spectinomycin analogue, was eight to 16 times more active than spectinomycin. All the quinolones tested were very active against all strains and may provide an effective alternative for the treatment of resistant $H$ influenzae in genitourinary infections.

The aetiological role of Haemophilus influenzae has been reported in neonatal, ${ }^{1-4}$ obstetrical, ${ }^{4-7}$ and gynaecological infections, ${ }^{8-13}$ and in urethritis, ${ }^{114-16}$ acute epididymo-orchitis, ${ }^{17}$ and urinary tract infections. ${ }^{1819}$ It is thought to be a cause of sexually transmitted disease (STD) ${ }^{20}$ Moreover, mixed infections with other agents of STD, including Neisseria gonorrhoeae, Chlamydia trachomatis, Ureaplasma urealyticum, and Mycoplasma hominis, are common. ${ }^{11} 1416$ In 1982-5 we isolated 60 strains of $H$ influenzae from patients with genital and urinary tract infections. In the present study we classified the biotype and capsular serotype of these strains and investigated their susceptibility to eight antibiotics used for genital and urinary infections: ampicillin, chloramphenicol, tetracycline, minocycline, erythromycin, kanamycin, spectinomycin, and rosoxacin. We also assessed the usefulness of the following newer antibiotics as alternatives to the conventional drugs: trospectomycin (U-63366), a new spectinomycin analogue; roxithromycin (RU28965), a new macrolid antibiotic; and the new

Address for reprints: Dr I Casin, Service de Bactériologie-Virologie, Hôpital Saint-Louis, 1 avenue Claude Vellefaux, 75010 Paris, France.

This study was presented in part at the 25th ICAAC, 1985, Minneapolis, Minnesota, USA

Accepted for publication 10 October 1987 quinolone derivatives, pefloxacin, norfloxacin, ofloxacin, and ciprofloxacin.

\section{Patients, materials, and methods}

BACTERIAL STRAINS

The $H$ influenzae strains evaluated were clinical isolates from adult patients with urinary or genital symptoms. Nineteen were isolated from vaginal secretions, one from a woman with bartholinitis, 37 from male urethral exudates, and three from urine.

\section{IDENTIFICATION PROCEDURES}

Requirements were assessed on tripticase soy agar (TSA, Bio-Mérieux, France) with Taxo Haemophilus differentiation strips (BBL, Microbiology Systems, Cokeysville, Maryland, USA).

The synthesis of porphyrins and porphobilinogen from $\delta$-aminolaevulinic acid ( $\delta$-ALA) was investigated as described by Kilian et al. ${ }^{21}$ The production of urease, ornithine decarboxylase, and indole was tested with the API-10E kit (API System, La Balme les Grottes, France) inoculated heavily with the growth from a 24 hour culture on chocolate agar supplemented with $1 \%$ Isovitalex (Bio-Mérieux, France). The classification of biotypes followed the scheme of Kilian et al. ${ }^{21}$ 
The capsular type of encapsulated $H$ influenzae strains was assessed by slide agglutination using a specific antiserum to type $b$ and pooled antisera to types a, c, d, e, and f (Phadebact Haemophilus test, Pharmacia Diagnostic, Sweden).

\section{DETECTION AND CHARACTERISATION OF $\beta$ \\ LACTAMASE}

Production of $\beta$ lactamase was detected by the rapid chromogenic cephalosporin test (Cefinase, BioMérieux, France).

The characterisation of $\beta$ lactamase was carried out by analytical isoelectric focusing in polyacrylamide gel on an LKB 2117 Multiphor instrument (Sweden) according to a method described previously. ${ }^{22}$ Two Escherichia coli $\mathrm{K} 12$ strains containing the plasmids pSF 2124 (colE1::Tn3) and RP4, which code respectively for TEM1 and TEM2 type $\beta$ lactamases, were used as reference for isoelectric points.

\section{ANTIBIOTIC SUSCEPTIBILITY TEST}

We used Mueller-Hinton agar supplemented with 5\% Filde's extract to test for susceptibility to the following antimicrobial agents: ampicillin (Beecham), tetracycline hydrochloride (Rhône Poulenc), minocycline (Lederlé), chloramphenicol, erythromycin, roxithromycin, and ofloxacin (Roussel-Uclaf), kanamycin (Bristol), spectinomycin and trospectomycin (U63366) (Upjohn), rosoxacin (Winthrop), pefloxacin (Roger Bellon), norfloxacin (Merck, Sharp and Dohme), and ciprofloxacin (Bayer-Pharma).

Minimum inhibitory concentrations (MICs) were measured by agar dilution. Agar plates containing serial dilutions of antibiotics were inoculated with a Steers type replicator. Colonies from overnight culture on chocolate agar plates were suspended in sterile saline to a density of $0.5 \mathrm{MacFarland}$ 's scale and diluted to give a concentration of about $10^{6}$ colony forming units (CFU) a spot. Culture plates were incubated at $37^{\circ} \mathrm{C}$ in an aerobic atmosphere for 24 hours. The MIC was defined as the lowest concentration of antibiotic that completely inhibited visible growth. Reference strains Staphylococcus aureus ATCC 25923 and $E$ coli ATCC 25922 were included in each experiment.
Table 2 Minimum inhibitory concentrations (MICs) of 14 antibiotics against 60 strains of Haemophilus influenzae

\begin{tabular}{|c|c|c|c|}
\hline \multirow[b]{2}{*}{ Antibiotics } & \multirow{2}{*}{$\begin{array}{l}\text { No of } \\
\text { strains }\end{array}$} & \multicolumn{2}{|l|}{$M I C(m g / l)$} \\
\hline & & Range & $M I C_{90}$ \\
\hline \multicolumn{4}{|l|}{ Ampicillin: } \\
\hline Sensitive & 50 & $0.03-0.5$ & 0.5 \\
\hline Resistant & 10 & $16-\geqslant 64$ & $\geqslant 64$ \\
\hline \multicolumn{4}{|l|}{ Kanamycin: } \\
\hline Sensitive & 58 & $1-4$ & 2 \\
\hline Resistant & 2 & $\geqslant 128$ & $\geqslant 128$ \\
\hline Spectinomycin & 60 & $4-8$ & 4 \\
\hline Trospectomycin & 60 & $0 \cdot 25-1$ & 0.5 \\
\hline \multicolumn{4}{|l|}{ Tetracycline: } \\
\hline Sensitive & 43 & $0 \cdot 25-2$ & 1 \\
\hline Resistant & 17 & $8-64$ & 32 \\
\hline Minocycline & 60 & $0 \cdot 12-8$ & 0.5 \\
\hline Chloramphenicol & 60 & $0 \cdot 5-1$ & 0.5 \\
\hline Erythromycin & 60 & $0 \cdot 5-8$ & 4 \\
\hline Roxithromycin & 60 & $4-32$ & 8 \\
\hline Pefloxacin & 60 & $0.03-0.25$ & 0.06 \\
\hline Rosoxacin & 60 & $0.016-0.25$ & 0.125 \\
\hline Norfloxacin & 60 & $0.03-0.25$ & 0.125 \\
\hline Ofloxacin & 60 & $0.008-0.03$ & 0.016 \\
\hline Ciprofloxacin & 60 & $0.008-0.03$ & 0.03 \\
\hline
\end{tabular}

MIC $_{n_{0}}=$ MIC for $90 \%$ of the strains.

\section{Results}

BIOTYPES AND CAPSULAR TYPES

Table 1 shows the correlation between the anatomical origin of the $H$ influenzae isolates and their biotypes and capsular types. Most of the strains belonged to biotypes III (28 strains) and IV ( 25 strains). All but two strains were non-capsulated.

\section{SUSCEPTIBILITY TESTING}

Table 2 shows the ranges of MICs and the MIC of each antibiotic required to inhibit $90 \%$ of the isolates (MIC 90). Ten out of the $60 \mathrm{H}$ influenzae strains tested were $\beta$ lactamase producing and had MICs of ampicillin ranging fron 16 to $64 \mathrm{mg} / \mathrm{l}$ or more. Seventeen strains were resistant to tetracycline (with MICs of 8 to $64 \mathrm{mg}$ / 1). MICs of minocycline were $8 \mathrm{mg} / 1$ or less for all strains. MICs of kanamycin ranged from 1 to $128 \mathrm{mg} / \mathrm{l}$ or more. Two strains were resistant to this compound. Trospectomycin (U-63366) was eight to 16 times more active than spectinomycin. All strains tested were fully susceptible to chloramphenicol (with MICs of 0.5-1

Table 1 Correlation between anatomical origin, biotype, and capsular type of 60 strains of Haemophilus influenzae

\begin{tabular}{|c|c|c|c|c|c|c|c|c|c|}
\hline \multirow{2}{*}{$\begin{array}{l}\text { Anatomical origin } \\
\text { of strains }\end{array}$} & \multirow[b]{2}{*}{ No } & \multicolumn{5}{|c|}{ Biotype } & \multicolumn{3}{|c|}{ Capsular type } \\
\hline & & $I$ & $I I$ & $I I I$ & $I V$ & $\boldsymbol{V}$ & $\bar{b}$ & acdef & $A c p^{a}$ \\
\hline $\begin{array}{l}\text { Vaginal secretions } \\
\text { Bartholin's duct } \\
\text { Urethral exudates } \\
\text { Urine }\end{array}$ & $\begin{array}{r}19 \\
1 \\
37 \\
3\end{array}$ & $\begin{array}{l}1 \\
0 \\
1 \\
0\end{array}$ & $\begin{array}{l}1 \\
0 \\
2 \\
0\end{array}$ & $\begin{array}{r}7 \\
0 \\
19 \\
2\end{array}$ & $\begin{array}{r}8 \\
1 \\
15 \\
1\end{array}$ & $\begin{array}{l}2 \\
0 \\
0 \\
0\end{array}$ & $\begin{array}{l}0 \\
0 \\
0 \\
0\end{array}$ & $\begin{array}{l}1 \\
0 \\
1 \\
0\end{array}$ & $\begin{array}{r}18 \\
1 \\
36 \\
3\end{array}$ \\
\hline Total & 60 & 2 & 3 & 28 & 25 & 2 & 0 & 2 & 58 \\
\hline
\end{tabular}

a-Acp $=$ acapsular strains. 
$\mathrm{mg} / \mathrm{l})$. Roxithromycin was slightly less active than erythromycin.

All quinolones tested exhibited a high activity against all strains. Ciprofloxacin and ofloxacin had the lowest MICs.

CHARACTERISATION OF $\beta$ LACTAMASE

The same isoelectric focusing pattern was obtained from crude extracts of the $10 \beta$ lactamase producing strains of $H$ influenzae and was similar to that of the TEM1 type $\beta$ lactamase produced by pSF 2124 .

\section{Discussion}

$H$ influenzae is not usually considered to be part of the normal flora of the genital tract: it has been recovered from none to $1 \%$ of symptomless women, pregnant or not, ${ }^{23-26}$ and from none to $9 \%$ of symptomless men. ${ }^{14-16}$ $H$ influenzae strains presented in this study were recovered from symptomatic patients. When isolated from urine, cultures showed bacteriuria of $10^{4} / \mathrm{ml}$ or more. All urethral and cervicovaginal specimens showed numerous polymorphonuclear leucocytes on Gram staining, and cultures yielded $H$ influenzae purely or predominantly. Eight patients yielded a concomittant genital pathogen: $\boldsymbol{N}$ gonorrhoeae (in 1 patient), $C$ trachomatis (1), Trichomonas vaginalis (3), and Candida albicans (3).

Since the first descriptions of genital and neonatal infections due to $H$ influenzae, the number of cases reported has increased appreciably during the past 15 years, which suggests a possible pathogenic role of this organism in gynaecological, obstetrical, and neonatal infections. Nevertheless the aetiological role of haemophili in adult vaginitis and urethritis in man is less well established. ${ }^{14202728}$

The pathogenicity of $H$ influenzae strains is closely related to the possession of capsular polysaccharide. Most strains isolated in invasive disease of infants and young children are encapsulated, and nearly all are type $b .{ }^{21}$ In obstetrical and neonatal systemic infections as well as in pelvic inflammation, both typable and non-typable $H$ influenzae strains have been implicated. As noted in this and other reports, ${ }^{132729}$ acapsulated strains predominate in the lower female genital tract and male urethra. No capsulated strain was found by Wallace et al in genital infections not associated with bacteraemia ${ }^{4}$ or by Sturm in male urethritis. ${ }^{16}$

Classification into biotypes according the scheme of Kilian et al has shown a biotype distribution of genital $H$ influenzae strains different from that of nasopharyngeal strains. Our results agree with those in other reports, which show the predominance of biotype IV $H$ influenzae strains in the genitourinary tract. ${ }^{427}$ These findings and those of Barenkamp et al showing a common outer membrane protein profile of strains isolated from neonates with sepsis, ${ }^{30}$ led Wallace et al to suggest that non-typable biotype IV $H$ influenzae strains might have a particular affinity for the genital tract and special virulence for neonates ${ }^{13}$ but other data do not support Wallace's opinion. ${ }^{331}$

Most reports on the resistance of haemophili to antimicrobials deal with systemic or oropharyngeal infections, and few concern genitourinary isolates. In this study $18(30 \%)$ strains were found to be resistant to one or several antibiotics. Resistance to tetracycline alone occurred in eight strains and associated with ampicillin resistance in nine strains. The two kanamycin resistant strains were also resistant to ampicillin and tetracycline. These numbers were higher than those reported in a nationwide French study in 1982 that excluded genitourinary isolates, ${ }^{32}$ and also than those reported by Albritton et $a l^{9}$ and Wallace $e t a l^{13}$ in genital and neonatal $H$ influenzae strains.

The production of TEM1 like $\beta$ lactamase was responsible for ampicillin resistance in the strains studied. We did not detect strains producing ROB-1 $\beta$ lactamase, the new type of plasmid determined $\beta$ lactamase found in two $H$ influenzae strains pathogenic to man and similar to the ROB-1 produced by the porcine pathogen $H$ pleuropneumoniae. ${ }^{33}$ Neither did we identify ampicillin resistant non- $\beta$-lactamase producing $H$ influenzae strains. ${ }^{34}$

Ofloxacin and ciprofloxacin may provide an effective alternative for the treatment of resistant $H$ influenzae in genitourinary infections. They are also effective in vitro against genital pathogens such as $N$ gonorrhoeae,$^{35} \mathrm{H}$ ducreyi ${ }^{36}$ and to a lesser extent, $C$ trachomatis $^{37}$ and $U$ urealyticum. ${ }^{38}$ Recent clinical trials with these compounds showed an excellent cure rate of gonococcal and non-gonococcal urethritis in men. ${ }^{39}{ }^{40}$ Further clinical studies with these agents in the treatment of STD seem to be warranted.

Few drugs are effective against both gonococcal and non-gonococcal genital infection, and tetracyclines are the most widely used. The high rate of resistance to tetracycline alone $(13 \%)$ or associated with resistance to other antibiotics as found in this study, has to be kept in mind because the common use of these antibiotics is likely to maintain a selective pressure on the genital bacteria. Studies have shown the spread of tetracycline resistance in, among other genera isolated from the genital tract, $M$ hominis, $U$ urealyticum, Gardnerella vaginalis, ${ }^{41}$ Streptococcus agalactiae, ${ }^{42}$ $H$ ducreyi (Sanson-Le Pors MJ, et al, unpublished observation), and $N$ gonorrhoeae. ${ }^{43}$

In conclusion, if we consider the possibility that the genitourinary tract environment favours plasmid transfer between bacterial species as well as genera, and as multiresistant strains of $H$ influenzae appear to 
be commonly recovered from patients with STD, it is important to monitor the trends in antimicrobial susceptibility of these organisms.

\section{References}

1 Khuri-Bulos N, McIntosh K. Neonatal Haemophilus influenzae infection. Report of eight cases and review of the literature. Am J Dis Child 1975;129:57-67.

2 Pickering L, Simon FA. Reevaluation of neonatal Haemophilus influenzae infections. South Med J 1977;70:205-7.

3 Pinon G, Quentin R, Dubray G. Hétérogénéité des souches de Haemophilus influenzae d'origine génitale et néonatale: analyse des sérotypes capsulaires, des biotypes, des profils électrophorétiques des protéines de membrane externe et du LPS. Ann Inst Pasteur Microbiol 1986;137B:195-205.

4 Wallace RJ, Baker CJ, Quinones FJ, Hollis DG, Weaver RE, Wiss K. Non typable Haemophilus influenzae (biotype 4) as a neonatal, maternal, and genital pathogen. Rev Infect Dis 1983;5:123-36.

5 Branefors P, Elgefors B, Olegard R. Intrauterine infection by noncapsulated Haemophilus influenzae in a case of maternal immunodeficiency. Scand J Infect Dis 1980;12:70-3.

6 Gibson M, Preston PW. Haemophilus influenzae amnionitis associated with prematurity and premature membrane rupture. Obstet Gynecol 1978;52:70-2.

7 Weinstein MP, Fernando NK, Colburn DW. Pelvic infections after cesarean section: the role of Haemophilus influenzae. Am J Infect Contr 1980;8:18-21.

8 Albritton W, Hammond GW, Ronald AR. Bacteremic Haemophilus influenzae genitourinary tract infections in adults. Arch Intern Med 1978;138:1819-21.

9 Depass EE, Fardy PW, Boulos JB, Abear EM. Haemophilus influenzae pyosalpingitis. Can Med Assoc J 1982;126:1417-8.

10 Eschenbach DA, Buchanan TM, Pollock HM, et al. Polymicrobial etiology of acute pelvic inflammatory disease. $N$ Engl $J$ Med 1975;293:166-71.

11 Hall GD, Washington II JA. Haemophilus influenzae in genitourinary tract infections. Diagn Microbiol Infect Dis 1983;1:65-70.

12 Nuchowicz A, Vanoudenhove JL, Serruys-Schoutens E. Infections gynécologiques à Haemophilus influenzae chez l'adulte. $\mathrm{La}$ Presse Médicale 1985;14:409-11.

13 Wallace RJ, Muscher DM, Septimus EJ, et al. Haemophilus influenzae infections in adults: characterization of strains by serotypes, biotypes, and B-lactamase production. J Infect Dis 1981;144:101-6.

14 Bowie WR, Pollock HM, Forsyth PS, et al. Bacteriology of the urethra in normal men and men with nongonococcal urethritis. J Clin Microbiol 1977;6:482-8.

15 Messing M, Sottnek FO, Biddle JW, Schlater LK, Kramer MA, Krauss SJ. Isolation of Haemophilus species from the genital tract. Sex Transm Dis 1983;10:56-61.

16 Sturm AW. Haemophilus influenzae and Haemophilus para-influenzae in nongonococcal urethritis. $J$ Infect Dis 1986;153:165-7.

17 Thomas D, Simpson K, Ostojic H, Kaul A. Bacteremic epididymo-orchitis due to Haemophilus influenzae type B.J Urol 1981;26:832-3.

18 Granoff DM, Roskes S. Urinary tract infection due to Haemophilus influenzae type B. J Pediat 1974;84:414-6.

19 Schvit KE. Isolation of Haemophilus in urine cultures from children. J Pediat 1979;95:565-6.

20 Fuzi M. Haemophili in sexually transmitted diseases. Lancet 1980;ii:476.

21 Kilian M, Sorensen I, Frederiksen W. Biochemical characteristics of Haemophilus influenzae in relationship to source of isolation and antibiotic resistance. J Clin Microbiol 1978;7:519-23.

22 Sanson-Le Pors MJ, Casin I, Ortenberg M, Peroi Y. In vitro susceptibility of thirty strains of Haemophilus ducreyi to several antibiotics including six cephalosporins. $J$ Antimicrob
Chemother 1983;11:271-80.

23 Beargie K, Lynd P, Tucker E, Duhring J. Perinatal infection and vaginal flora. Am J Obstet Gynecol 1975;122:31-3.

24 Goplerud CP, Ohm MJ, Galask RP. Aerobic and anaerobic flora of the cervix during pregnancy and the puerperium. Am JObstet Gynecol 1976;126:858-65.

25 McCormack WH, Evrard JR, Laughlin CF, et al. Sexually transmitted conditions among women college students. Am J Obstet Gynecol 1981;139:130-3.

26 Tashjian JH, Coulam CB, Washington II JA. Vaginal flora in asymptomatic women. Mayo Clin Proc 1976;51:557-61.

27 Albritton WL, Penner S, Slaney L, Brunton JL. Biochemical characteristics of Haemophilus influenzae in relationship to source of isolation and antibiotic resistance. J Clin Microbiol 1978;7:519-23.

28 Deming JE. Haemophilus influenzae vaginitis. Northwest Medicine 1955;59:992-3.

29 Albritton WL, Brunton JL, Meier M, Bowman MN, Slaney LA. Haemophilus influenzae: comparison of respiratory tract isolates with genitourinary tract isolates. J Clin Microbiol 1982;16:826-31.

30 Barenkamp SJ, Munson RS, Granoff DM. Outer membrane protein and biotype analysis of pathogenic non typable Haemophilus influenzae. Infect Immun 1982;36:535-40.

31 Kleiman MB, Reynolds JK, Schreiner RL, Smith JW. Failure to demonstrate special virulence of non typable Haemophilus influenzae biotype 4 in neonatal sepsis. $J$ Infect Dis 1983;148:615.

32 Dabernat $\mathrm{H}$. L'infection à Haemophilus. Résultats de l'enquête multicentrique concernant la sensibilité aux antibiotiques, 1982, Paris, France. Pathol Biol (Paris) 1983;31:77-9.

33 Medeiros AA, Levesque R, Jacoby GA. An animal source for the ROB-1 $\beta$-lactamase of Haemophilus influenzae type $b$. Antimicrob Agents Chemother 1986;29:212-5.

34 Parr TR, Bryan LE. Mechanism of resistance of an ampicillin resistant, $\beta$-lactamase negative clinical isolate of Haemophilus influenzae type b to $\beta$-lactam antibiotics. Antimicrob Agents Chemother 1984;25:747-53.

35 Peeters M, Van Dyck E, Piot P. In vitro activities of the spectinomycin analog U-63366 and four quinolone derivatives against Neisseria gonorrhoeae. Antimicrob Agents Chemother 1984;26:608-9.

36 Sanson-Le Pors MJ, Casin IM, Thebault MC, Arlet G, Perol Y. In vitro activity of U-63366, a spectinomycin analog, roxithromycin (RU 28965), a new macrolid antibiotic, and five quinolone derivatives against Haemophilus ducreyi. Antimicrob Agents Chemother 1986;30:512-3.

37 Heessen FWA, Muytjens HL. In vitro activities of ciprofloxacin, norfloxain, pipemidic acid, cinoxacin, and nalidixic acid against Chlamydia trachomatis. Antimicrob Agents Chemother 1984;25:123-4.

38 Aznar J, Caballero C, Lozano MC, De Miguel C, Palomares JC, Perea EJ. Activities of new quinolone derivatives against genital pathogens. Antimicrob Agents Chemother 1985;27:76-8.

39 Arya OP, Hobson D, Hart CA, Bartzokas C, Pratt BC. Evaluation of ciprofloxacin $500 \mathrm{mg}$ twice daily for one week in treating uncomplicated gonococcal, chlamydial, and non-specific urethritis in men. Genitourin Med 1986;62:170-4.

40 Morel P, Casin I, Bianchi A, Dolivo M, Perol Y. Traitement par ofloxacine (RU 43280) des uréthrites masculines bactériennes non compliquées. Pathol Biol (Paris) 1986;34:502-4.

41 Roberts MC, Hillier SL, Hale J, Holmes KK, Kenny GE Tetracycline resistance and tet $M$ in pathogenic urogenital bacteria. Antimicrob Agents Chemother 1986;30:810-2.

42 Burdett V. Identification of tetracycline-resistant R-plasmids in Streptococcus agalactiae (group B). Antimicrob Agents Chemother 1980;18:753-60.

43 Morse SA, Johnson SR, Biddle JW, Roberts MC. High level tetracycline resistance in Neisseria gonorrhoeae is result of acquisition of streptococcal tet $M$ determinant. Antimicrob Agents Chemother 1986;30:664-70. 